\title{
Política comparada, Estado y democracia en la teoría de Stein Rokkan
}

\author{
Fernando Barrientos del Monte*
}

\begin{abstract}
Resumen
El politólogo noruego Stein Rokkan fue uno de los científicos sociales más importantes de la posguerra, pero su contribución intelectual para la consolidación y desarrollo de la ciencia política contemporánea es aún prácticamente desconocida en el ámbito latinoamericano. Su original y a la vez compleja "Teoría del desarrollo político, de la democracia y del pluralismo" se basa en una serie de modelos para el análisis de la construcción de los Estados-nación y los procesos de democratización en Europa occidental. Si bien tiene como foco de análisis la historia de Europa, no debe considerarse como una "teoría estrictamente europea", sino como un cuerpo de conceptos que ofrecen una perspectiva de análisis para otras experiencias histórico-políticas como es el caso de los países latinoamericanos.
\end{abstract}

Palabras clave: Política comparada - democratización - clivajes.

\begin{abstract}
The Norwegian political scientist Stein Rokkan has been recognized as one of the most important social scientists of the post-war period. However, his intellectual contribution to the consolidation and development of contemporary political science is practically unknown in the Latin-American context. His original and complex "Political Development Theory of Democracy and Pluralism" is based on a series of models for the analysis of nation-states construction and the democratization processes in Western Europe. Although the history of Europe constitutes the focus of his analysis, his work should not be considered a "restrictively European theory" but rather a series of concepts which offer a perspective of analysis for other historical-political experiences such as those in Latin American countries.
\end{abstract}

Keywords: Comparative politics - democratization - cleavages.

* Doctor en Ciencia Política por el Istituto Italiano di Scienze Umane y la Universidad de Florencia, Italia. Director del Departamento de Estudios Políticos de la Universidad de Guanajuato, México. Correo electrónico: f.barrientos@ugto.mx 


\section{INTRODUCCIÓN}

Stein Rokkan (1921-1979) fue uno de los más importantes científicos sociales de la segunda parte del siglo XX; es considerado fundador ${ }^{1}$ y uno de los "grandes maestros de la ciencia política", además de una figura eminente e influyente en la historia de las ciencias sociales en Europa y Estados Unidos. Politólogo, sociólogo e historiador de primer orden, sus investigaciones y trabajos colectivos se consideran hoy absolutamente necesarios; tuvo una enorme influencia en el desarrollo y consolidación de las ciencias sociales en la posguerra como organizador y fundador de estructuras para la investigación comparada. Su contribución más importante radica en la originalidad de su propuesta teórica para el estudio del desarrollo político europeo, basada en su programa de investigación, considerada como una macrosociología histórico-comparada. El legado intelectual de S. Rokkan es poco conocido -o poco difundido- en el ámbito de la ciencia política y la sociología en casi toda Latinoamérica, pues sólo se conocen algunos de sus ensayos, y en general, de segunda mano su extensa obra teórica. Las condiciones políticas y sociales de la segunda mitad del siglo XX en América Latina se enmarcaban en un contexto de sistemas autoritarios, golpes de Estado recurrentes y una sociedad civil poco participativa; la incipiente ciencia política en la región giraba en torno al marxismo, las teorías del desarrollo dependiente y el estudio de los sistemas "burocrático-autoritarios". Harían falta algunos lustros más para que en el contexto de los procesos de democratización empezaran a permear otras perspectivas de análisis. En 1981, apenas dos años después de su muerte, se publicó uno de sus pocos textos traducidos al español; era un ensayo sobre los esfuerzos de la investigación comparativa que bien prefiguraba la contemporánea aceleración de la internacionalización de las ciencias sociales a partir de la investigación conjunta de diversos centros en ámbitos culturales diversos y apoyados por las nuevas tecnologías, en específico las computadoras de tercera generación (Rokkan, 1981). Tal vez uno de sus conceptos analíticos más difundido y citado sea el de "clivajes" (cleavages), el cual apareció por primera vez en un trabajo publicado junto con Seymour Martin Lipset (1967) y traducido al español en apenas una recopilación de algunos textos esenciales para el estudio de la ciencia política (Almond et al., 2000). La teoría de los clivajes tuvo gran penetración en América Latina y se ha reproducido con relativo éxito a partir de diversos trabajos que encontraron en dicha teoría un marco explicativo para el (re)surgimiento de los partidos políticos en el contexto de los procesos de democratización a finales del siglo XX en la región (Dix, 1989; Scully, 1995; Moreno, 1999; Roberts y Wibbels, 1999).

¿Por qué Rokkan es considerado un "maestro de la ciencia política"? Partiendo de los criterios de Norberto Bobbio (1994: 215-216) para referirse al legado intelectual de Max Weber, los cuales son retomados por Campus y Pasquino (2004) en una excelente recopilación de ensayos sobre otros clásicos contemporáneos de la ciencia política -entre ellos A. Downs, D. Easton, J. Linz, S.M. Lipset y otros-, un "clásico" tiene tres características específicas: i) es considerado como un intérprete auténtico y único de su tiempo, y de quien su obra es

1 Stein Rokkan es considerado fundador de la ciencia política moderna junto con G. Sartori, Juan Linz, Mattei Dogan, Hans Daalder, Eric Allardt, S.N. Eisenstadt y otros (Daalder, 1997). 
considerada como un instrumento indispensable para comprenderlo; ii) es siempre actual en cualquier época, incluso cada generación siente la necesidad de releerlo y reinterpretarlo releyéndolo; y iii) ha construido teorías-modelo de las cuales nos servimos para comprender la realidad, incluso una realidad diferente a aquella de la cual derivó y a la cual aplicó, y con los años se convirtieron en auténticas categorías mentales. Tal vez la obra de Rokkan se encuentra más inclinada hacia la tercera característica, pero no menos a las otras dos. Su legado intelectual ha sido objeto de análisis detallado de sociólogos y politólogos en publicaciones especiales: en 1980 la Rivista Italiana di Scienza Politica ( $n^{\circ}$ 3) y en 1995 la Revue Internationale de Politique Comparée $\left(\mathrm{n}^{\circ} 1\right)$ dedicaron sus páginas a la discusión de sus ideas y planteamientos más relevantes, y hasta ahora son las recopilaciones de ensayos más importantes sobre este intelectual. En 1981 el European Consortium for Political Research (ECPR) instituyó en su honor el Stein Rokkan Prize for Comparative Social Science Research para promover investigaciones en el ámbito de la sociología y la ciencia política comparadas. Posteriormente, la International Political Science Association (IPSA) creó en su memoria el Stein Rokkan Award que se da anualmente. En el 2002 la Universidad de Bergen creó el Stein Rokkan Centre for Social Studies para continuar promoviendo investigaciones interdisciplinarias en el campo de las ciencias sociales; y en el 2006 el gobierno de Noruega y el Instituto Universitario Europeo de Florencia crearon la Stein Rokkan Chair in Comparative Politics.

La ausencia de un autor como Rokkan en el ámbito intelectual latinoamericano radica, además de lo señalado anteriormente, en tres cuestiones: i) dado su origen noruego, Rokkan se consideraba a sí mismo "un hombre de la periferia, que amaba el pluralismo cultural pero al mismo tiempo se definía como un cosmopolita que no deseaba que se impusiera ninguna cultura local" (Allardt y Valen, 1981: 11-38). Por ello, las referencias históricas de su teoría se centran en el contexto europeo, lo que quizá en su momento fue poco atractivo para los intelectuales latinoamericanos de su época; ii) desde sus primeros trabajos ya se reflejaba la influencia de autores como K. Arrow, H. Lasswell, P. Lazarsfeld, R.K. Merton, O. Morgenstern y T. Parsons, entre otros, quienes como el mismo Rokkan consolidaron las ciencias sociales y específicamente la sociología y la ciencia política en el mundo occidental entre las décadas de 1950 a 1970; son autores que no eran referencia usual para el mundo intelectual latinoamericano, donde imperaban las diversas corrientes del marxismo, y las teorías dominantes no reflejaban un interés sobre el desarrollo político y los procesos de democratización en la Europa de la posguerra, sino sobre la dinámica del socialismo versus capitalismo, y el posterior auge de las teorías de la dependencia ${ }^{2}$; iii) aunado a estas dos cuestiones, Rokkan no estaba interesado en productos finales, sino en el proceso de investigación mismo, y si bien había previsto una obra que recopilara su compleja teoría, murió antes de poder llevar a cabo este proyecto y su pensamiento científico quedó disperso en más de 200 trabajos entre artículos, ponencias, conferencias y capítulos de libros. Gracias al gran esfuerzo intelectual y de investigación de Peter Flora, en 1999 se publicó por primera vez en una sola obra la compleja teoría del desarrollo político europeo de Rokkan (2002) bajo el título State Formation, Nation Building, and Mass Politics

2 Un ejemplo del debate de la época se puede ver en el ensayo de Umberto Cerroni (1979). 
in Europe. The Theory of Stein Rokkan. Dicha publicación permite actualmente estudiar sistemáticamente su propuesta teórica.

A lo largo de este artículo se elabora una lectura introductoria pero sistemática de la obra de S. Rokkan, centrándonos principalmente en: i) los aspectos biográfico-intelectuales y sus aportaciones para la consolidación de las ciencias sociales; ii) los elementos centrales de su modelo teórico del "desarrollo político europeo" que corresponden a la segunda y tercera fases de la maduración de su obra: la construcción del Estado y la formación de la nación; y iii) su "Teoría de la democracia y del pluralismo" que desarrolló a partir del estudio de la estructuración de la política de masas en Europa occidental, y que corresponde a la primera fase de su obra intelectual: la democratización y su quiebre, las fracturas y las respuestas organizativas. Las tres fases en conjunto conforman su "Teoría del desarrollo político". Profundizaremos en mayor medida en su teorización sobre la democracia, ya que fue inicialmente el fundamento que lo llevó a la elaboración de su gran teoría. El objetivo central es demostrar que la "Teoría del desarrollo político" de Rokkan, y en especial los conceptos contenidos en el estudio de los procesos de democratización, no obstante que su foco de análisis está centrado en la historia de Europa, no es por ello una "teoría estrictamente europea", sino un cuerpo de conceptos que ofrecen una perspectiva de análisis para otras experiencias histórico-políticas, como lo son propiamente los países latinoamericanos.

\section{ASPECTOS BIOGRÁFICO-INTELECTUALES}

Stein Rokkan nació el 4 de julio de 1921 en uno de los extremos de las islas de Lofoten, al norte de Noruega; hijo de un profesor, creció en la ciudad de Narvik hasta 1939, año en que ingresó a la Universidad de Oslo donde estudió filología especializándose en lengua francesa. Sus estudios universitarios fueron interrumpidos en 1943 cuando los alemanes cerraron la Universidad y tuvo que refugiarse en las islas de Lofoten. Retomó sus estudios después de la liberación y obtuvo resultados académicos brillantes que le valieron el reconocimiento en toda la Universidad. Persuadido por el filósofo Arne Næss, uno de los principales exponentes del positivismo lógico de la Escuela de Viena, continuó con estudios de filosofía obteniendo en 1948 un Magíster en Filosofía con una disertación sobre la filosofía política de David Hume. En ese periodo empezó a participar activamente en redes universitarias interesadas en el desarrollo de las ciencias sociales y a crear contactos con la UNESCO en París. Trabajó inicialmente como asistente de investigación de Næss en un proyecto sobre la "Democracia", organizando y analizando un conjunto de trabajos de expertos internacionales sobre el tema; y junto a Richard McKeon se convierte en editor de la obra Democracy in a World of Tensions, publicada en 1951. Entre 1948 y 1950 obtiene financiamiento de la Fundación Rockefeller que le permite llevar a cabo un periodo de investigación en la Universidad de Columbia -trabajando con Lazarsfeld-y en Chicago. Entre 1950 y 1951 trabajó un periodo en la London School of Economics, donde fue influenciado fuertemente por la obra de Thomas Marshall, quien se interesaba sobre todo en las cuestiones de ciudadanía, clases sociales y desarrollo político (véase Marshall, 1998). 
En 1951 Rokkan comienza a laborar en el Institute of Social Research (ISF) de Oslo, fundado un año antes por Eric Rinde. Financiado con recursos privados, el ISF se convierte en poco tiempo en la sede de importantes proyectos de investigación, y pronto Rokkan es nombrado director en esta área. En ese mismo año, en dicho Instituto se lleva a cabo la First International Working Conference on Social Mobility; los trabajos presentados fueron editados por Rokkan y Rinde, y publicados por la International Sociological Association (ISA). En el mismo año Rokkan fundó con otros científicos sociales la Organization for Comparative Social Research, que reunió inicialmente a investigadores para un estudio sobre el comportamiento docente en siete naciones. Posteriormente, el ISF hospedó el "Programa Noruego de Investigación Electoral", a partir del cual inició una estrecha colaboración con Henry Valen, otro importante estudioso de los procesos electorales. En 1958 ingresa como profesor-investigador de ciencia política comparada en el Christian Michelsen Institute de la Universidad de Bergen, y en 1966 obtiene una cátedra en la misma institución, lo que permitió crear un departamento fuertemente orientado a la política comparada. Rokkan fue un promotor único en su momento de la internacionalización de las ciencias sociales y un activo creador de organismos y estructuras universitarias para la investigación comparada; asumía nuevas iniciativas, organizaba congresos y grupos de investigación, y era un incansable escritor (Daalder, 1980: 350). Trabajar con la UNESCO le permitió tener contactos con instituciones y científicos sociales de rango internacional, permaneciendo fiel a dicha institución y sus organismos secundarios, en particular al International Social Science Council del cual fue presidente (1973-77). Fue también presidente de la IPSA de 1970 a 1973; vicepresidente de la ISA de 1966 a 1970; y presidente (1970-1976) y cofundador del ECPR junto a Jean Blondel y Peter de Janosi de la Ford Foundation, y Warren Miller del Inter-University Consortium for Political Research de Ann Arbor. Por diez años (1960-1970) Rokkan fue secretario del International Committee on Political Sociology (ICPS), siendo presidente Seymour Martin Lipset en el mismo periodo. El ICPS se transformó sustancialmente en una red de contactos personales entre estudiosos internacionales que compartían con Rokkan la aspiración de analizar grandes cambios sociales. Dicho Comité estaba originariamente afiliado a la ISA, pero el trabajo de sus miembros seguía también el ritmo de los convenios con la IPSA, por lo que en 1970 se transformó en un comité de investigación común a ambas organizaciones.

Rokkan tenía un interés particular en la promoción de las actividades de perfeccionamiento de la investigación social, por lo que creó varias escuelas de verano (summer schools) y data confrontation seminars con un acento específico en la comparación bajo el patrocinio del International Social Sciences Council. Quizá la contribución menos difundida de Rokkan fue la promoción, cuando no era nada común, del uso de las computadoras y programas especializados para el tratamiento de datos en las ciencias sociales en Europa occidental. Su red de contactos personales le ayudó a favorecer el arribo a Europa de especialistas estadounidenses que desarrollaron programas de software como Osiris y el SPSS. Dado que en casi todos los centros de investigación de Europa existía un atraso entre la elaboración de bases de datos y el rápido desarrollo de nuevas generaciones de computadoras, apoyó la creación del Computer Applications Group dentro del ECPR, el cual se constituyó por un grupo de jóvenes especialistas en software y de expertos en el análisis cuantitativo que trabajaban en centros como Bergen, Colonia, Ginebra, Leiden, Mannheim y Strathclyde; y 
tenía la tarea, además de asistir a cualquier departamento en Europa, de publicar información exhaustiva sobre nuevos programas para quienes elaboraban bases de datos en una sección del European Political Data Newsletter. Rokkan apreciaba el desarrollo de nuevos métodos de cartografía computarizada, y en el verano de 1977 organizó en Bergen un encuentro de expertos en este campo. En el desempeño de sus funciones como miembro de diversas organizaciones, Rokkan se convirtió en uno de los más importantes promotores de la internacionalización de las ciencias sociales. Consideraba que eran necesarios esfuerzos continuos de hombres e instituciones para desarrollar investigaciones del tipo cross-cultural (transculturales), cross-societal (trans-societales) y cross-national (transnacionales). Para Rokkan la investigación social con estas características y dimensiones requiere la recopilación de "datos" sobre comportamientos, actitudes e ideas en varios niveles de estructuración social; pero es el análisis comparativo lo que genera el avance en las ciencias sociales pues es la base de las generalizaciones y de la construcción de las teorías.

Fue uno de los primeros científicos sociales en entender el valor intelectual de las bases de datos para las ciencias sociales, pero era consciente de los "peligros" de las explicaciones "numerológicas"3. Creó el Norwegian Social Sciences Data Service que sirvió también para el ECPR Data Information Service. Dirigió varios proyectos de investigación de carácter internacional, muchos bajo el patrocinio de la UNESCO, lo que le permitió publicar diversos compendios y archivos de datos como la International Guide to Electoral Statistics (Rokkan y Meyriat, 1969) y los Data Archives for the Social Science, Comparing Nations (con Richard Merrit). Fue editor de Comparative Research Across Cultures and Nations (1968) y con Sydney Verba, Jean Viet y Alina Almasy del Comparative Survey Research (1969), entre muchas otras obras. Su desempeño fue siempre de colaboración, por lo que publicó numerosos trabajos en común con autores de diversos países, o compartiendo la responsabilidad de coordinador y editor, si bien Rokkan aparecía explícitamente como el autor principal o bien hacía la mayor parte del trabajo publicado. Entre los volúmenes que Rokkan coordinó y/o contribuyó se encuentran Party Systems and Voter Alignments: Cross-National Perspectives, con Seymour Martin Lipset (1967); Quantitative Ecological Analysis, con Mattei Dogan (1969); Mass Politics: Studies in Political Sociology, con Erik Allardt (1970), y otros más. Rokkan prefería la elaboración de ensayos parciales y menos trabajos finales, por ello la mayor parte de su obra politológica se publicó dispersamente en revistas científicas internacionales, como el seminal artículo The Structuring of Mass Politics in the Smaller European Democracies (1968) que fue un importante paso para el desarrollo de su macromodelo de Europa y que constituye uno de los principales capítulos de su obra Citizens, Elections, Parties publicada

3 En este aspecto es necesario aclarar que Rokkan compartía, con G. Sartori fundamentalmente, los efectos contraproducentes del "ansia cuantificadora". A diferencia de Rokkan, Sartori considera que la revolución behaviorista llevó a la ciencia política a convertirse en "precisa, más aún exacta, sobre cosas triviales" (véase Sartori, 1984). Rokkan, por el contrario, consideraba que la ciencia política sólo podía avanzar en la medida que los datos reforzaran los argumentos, y no que éstos fuesen sustituidos por aquéllos. Después de 25 años de la muerte de Rokkan, Sartori continúa con su argumento, pues para él la ciencia política "ha adoptado un modelo inapropiado de ciencia (extraído de las ciencias duras, exactas) y ha fracasado en establecer su propia identidad (como ciencia blanda) por no determinar su metodología propia" (Sartori, 2004), una afirmación que quizá no debería tomarse en serio. 
en 1970. Rokkan fue promotor y partícipe del proyecto The Smaller European Democracy (SED), iniciado en 1961 por Val Lorwin y al cual posteriormente se uniría Robert A. Dahl. El proyecto SED reunió a expertos de once pequeños países europeos, los que compartían el deseo de llevar a otra etapa la política comparada europea, dominada por las imágenes -continuamente erróneas- de los grandes países europeos. En uno de los productos del proyecto SED, el volumen editado por Dahl en 1966, Political Oppositions in Western Democracies, Rokkan publicó un importante ensayo sobre la política noruega titulado Norway: Numerical Democracy and Corporate Pluralism. El tema dominante en dicho artículo era la distinción entre canales de representación electoral propios de la "democracia numérica" y la realidad impuesta por los procesos decisionales de tipo corporativo; el artículo fue posteriormente publicado en otras revistas internacionales bajo el título Votes Count, Resources Decide (1975) y tuvo un enorme efecto para comprender las estructuras corporativas en los países europeos (Daalder, 1980: 354).

Rokkan era un asiduo congresista e incansable compilador de memorias, participaba en muchas reuniones con colegas para la realización de convenios de investigación, que consideraba instrumentos con los cuales impulsar proyectos ya existentes o iniciar otros nuevos. Rokkan se movía con cierta facilidad entre diversas disciplinas -ciencia política, historia, sociología-, con la capacidad de integrar las enseñanzas de los clásicos y las contribuciones más recientes, así como desarrollar modelos con el más elevado nivel de abstracción y las investigaciones empíricas más minuciosas dentro de la macro y la microhistoria. El estudio del desarrollo político europeo fue su área de estudio preferida, como respuesta a lo que le parecía una tendencia a la teorización excesivamente generalizante de los estudiosos norteamericanos. Ubicándose entre los límites de la política comparada, esta posición le permitió ser contemporáneamente un entusiasta y un escéptico. Su profundo conocimiento del análisis conductista lo llevó a tratar de encontrar "pruebas"; prefería análisis parciales, concienzudos y conclusivos, antes que apresuradas generalizaciones. Rokkan, como muchos otros científicos sociales, se movió a contracorriente: la idea dominante en las ciencias sociales de la posguerra era buscar explicaciones de los fenómenos sociales por medio de "leyes", es decir, la perspectiva nomológica-deductiva según la noción de ley, codificada en los procedimientos de la experimentación de las ciencias naturales. Sin embargo, en las ciencias sociales los resultados en términos de leyes universales regularmente han sido magros, y entre la teoría y la investigación empírica se presentaban cada vez más dudas (Mjøset, 2000: 382-383). Poco a poco los científicos sociales fueron elaborando versiones "modificadas" del enfoque nomológico-deductivo. En lo general, se desarrollaron dos grandes modificaciones: i) la noción de teoría como marco de orientación (law-oriented), a través de la cual se buscan regularidades limitadas, es decir, "cuasi-leyes" que no se aplican universalmente sino en contextos específicos -por ejemplo, la noción de teorías de medioalcance de Robert K. Merton-; y ii) la otra es la construcción de tipos ideales (Weber), es decir, teorías con las cuales se construyen orientaciones de actores y contextos ideales, esto es, "casos extremos" de conductas pero no "leyes universales".

Rokkan buscaba continuamente respuestas dirigiéndose al pasado y en el "mapa conceptual de Europa" que desarrolló, a lo largo de varios artículos y capítulos en obras colectivas, es 
evidente su ambición de crear un amplio esquema analítico bajo una perspectiva "topológicatipológica" basada en variables "condicionantes", "intervinientes" y "dependientes". Construyendo numerosas tipologías como el "mejor" camino para elaborar explicaciones de aquello que de otra forma parece un conjunto confuso de eventos históricos, buscó analizar las condiciones políticas de un determinado periodo con aquellas prevalecientes en el periodo precedente. El mapa es un retrato del desarrollo actual de Europa, de cada territorio, de grupos sociales y sus relaciones. Su esquema analítico principal es el "eje centroperiferia" con sus dimensiones económicas, culturales y políticas independientes. Sobresale la complementariedad entre el microanálisis y el macroanálisis, pues Rokkan se mueve fácil y constantemente entre estas dos visiones, reforzando argumentos y proponiendo nuevas tesis. Inicialmente podemos señalar que las innovaciones científico-sociales de Rokkan radican en al menos tres aspectos: i) en la elaboración de nuevos paradigmas interpretativos de la política, entre ellos la teoría de los "clivajes" (cleavages), considerada un "instrumento base" de los politólogos 4 ; ii) en la construcción de un sólido puente y de una robusta mediación entre dos grandes tradiciones de estudios políticos, la histórica-institucional europea y la empíricaconductista estadounidense; y iii) en la apertura de nuevas perspectivas de investigación sobre el desarrollo político de la Europa moderna y contemporánea al colocarla claramente en un solo "mapa" en toda su complejidad y con todos los numerosos problemas que han tenido que ser estudiados ulteriormente.

\section{EL ENFOQUE DEL DESARROLLO DE LA POLÍTICA}

Rokkan combinó dos "revoluciones" que caracterizaron a las ciencias sociales de los años cincuenta del siglo XX, principalmente en Norteamérica: el conductismo (behaviorism) y la política comparada. La estructuración de su obra teórica se fue construyendo a la par de su propuesta metodológica. Sus intereses giraban en torno a los procesos de la formación del Estado, la identidad nacional, la legitimidad, la participación y la distribución de las masas, y se concentró en el estudio del desarrollo político europeo, un desafío complejo que implicaba también una respuesta a la tendencia de los politólogos y sociólogos norteamericanos más influyentes a hacer generalizaciones teniendo como referencia los "Estados nuevos", tomando como modelo los países del denominado Tercer Mundo que ofrecían en cierta forma mayores elementos de control (Morlino, 1980: 19-45). A principios de esa década varios estudiosos consideraban que la ciencia política moderna se encontraba en un estado de atraso, que era provinciana, eurocéntrica, descriptiva, formalista, estática y monográfica (Morlino, 1980: 19). Gran parte del crecimiento de la ciencia política -y de la política comparada en específicoen la década de los cincuenta y en los años posteriores fue impulsado por el estudio del desarrollo político. El denominado Tercer Mundo fue el área que acaparó la mayoría de los esfuerzos intelectuales de toda una generación de científicos sociales entre politólogos, economistas, sociólogos, etc. La primera corriente que apareció se centró en el estudio

4 Es quizá Stefano Bartolini quien junto a Peter Mair han "puesto a prueba", y diríamos con suficiente éxito, la teoría de los clivajes en dos voluminosas obras: Identity, Competition, and Electoral Availability. The Stabilization of European Electorates, 1885-1985 (1990) y The Political Mobilization of the European Left, 1860-1980: The Class Cleavage (2000). 
del devenir de las nuevas naciones de África y Asia, mientras que una segunda corriente se abocó al estudio de hipótesis relacionadas con diversos aspectos de la modernización, como la industrialización, la urbanización, la educación, así como la democratización y la movilización política (Almond, 1999: 297-300). En esos años se constituyó el Committee on Comparative Politics del Social Sciences Research Council ${ }^{5}$, el cual promovía la formulación de proposiciones teóricas generales con la ambición de elaborar una "política comparada que consiguiera abarcar todos los sistemas políticos en todos los estadios del desarrollo a través del mundo y de la historia" (Pye, citado por Morlino, 1980: 20). El Committee inauguró un programa de conferencias y publicaciones destinadas a compendiar el saber y la erudición existentes acerca de los problemas y esquemas del desarrollo. Como ha señalado Almond (1999: 301), existía la convicción de que el desarrollo en el Tercer Mundo exigía no solamente una diversidad de políticas económicas, sino también instituciones políticas capaces de movilizar y actualizar recursos materiales y humanos. La premisa era que no podía haber desarrollo económico sin desarrollo político. Rokkan participó en el Committee, publicando algunos trabajos en la serie Studies in Political Development (ej. 1966), pero Ilegó a un punto donde explícitamente decidió tomar distancia de las posiciones de éste, que tendió a acumular indicadores cuantitativos y a elaborar análisis estadísticos descuidando la historia y las instituciones. Ya para mediados de la década de los sesenta nació una ola de críticas contra la investigación acerca del desarrollo que la calificaba de "imperialista" en el ámbito ideológico, pero sobre todo se criticó su perspectiva "positivista" (Almond, 1999: 307). Rokkan ya había dejado en claro su preferencia por el análisis concentrado en ámbitos territoriales limitados, como es el caso de los países de Europa -casos comparables por sus afinidades-, centrando su atención sobre todo en los grandes procesos histórico-sociales; incluso reivindicó de modo provocativo la libertad de estudiar también las obras literarias para comprender de mejor forma el desarrollo político de un país. Más que interesarse en el proceso mismo del desarrollo, como lo hacían la mayoría de quienes formaban el Committee, a Rokkan le intrigaba entender por qué los procesos de formación del Estado, de construcción de la nación y los procesos de democratización asumían formas diversas.

Mjøset (2000) divide la construcción de la obra de Rokkan en tres etapas, que corresponden con sus fases de maduración intelectual: i) sus experiencias tempranas en el estudio de la sociología comparada, donde es fuertemente influenciado por los trabajos de T. Parsons y K. Deutsch, principalmente; ii) el estudio de la democratización, fase en la que desarrolla la teoría de los clivajes con Lipset; y iii) el modelo y mapas de Europa, que corresponde a la maduración de sus propias ideas. Rokkan inicialmente analizó el proceso del desarrollo político de su propio país, Noruega, y posteriormente casi la totalidad de los países europeos continentales. Caracterizó su trabajo como un enfoque topológico-tipológico, a través del cual diseñó un complejo mapa conceptual de Europa, construyendo numerosos modelos (o tipologías). El esquema analítico de base es el eje centro-periferia con dimensiones económicas y culturales independientes (Rokkan, 1980: 437-470). Raramente habla de "teoría", y utiliza el menos ambicioso concepto de "modelo", y más precisamente de un "modelo de las fuentes

5 Integrado por G.A. Almond, L.W. Pye, S.P. Huntington, J. LaPalombara y S. Verba, entre otros. 
de las macrovariaciones entre los territorios de Europa occidental". No se trata de un único modelo, sino de modelos parciales, varias veces reelaborados-interrelacionados entre sí, que sucesivamente puso a prueba con éxito. El conjunto de modelos, vistos hoy de manera retrospectiva, posibilita hablar de una Teoría del desarrollo político europeo.

Sintéticamente podemos distinguir al menos cinco ideas-guía contenidas en la obra teórica de Rokkan:

1. Puso en primer plano una idea que iba en contracorriente en el clima cultural que caracterizaba a la ciencia política y la sociología de los años cincuenta, es decir, el peso de las herencias históricas (path dependence) en la conducta de los sujetos políticos y en las divisiones político-electorales reflejadas en el sistema de partidos y en el sistema electoral. Analizando inicialmente el caso noruego, Rokkan descubrió que el comportamiento electoral dependía mucho del "congelamiento" de oposiciones y lealtades que se habían forjado en el siglo precedente, durante los conflictos en el proceso de instauración de la democracia. En contraste con las perspectivas ahistóricas prevalecientes en la ciencia política, Rokkan observó con otro ángulo analítico la Europa contemporánea: buscó en el pasado lejano de cada país las causas de sus divisiones políticas internas, e identificó en las diferentes modalidades de formación de los Estados modernos y de los sucesivos procesos de democratización el origen de las variaciones en las configuraciones actuales de los sistemas políticos europeos.

2. En una segunda fase se centró en las diferencias geográficas al interior de cada país que inciden en el comportamiento político-electoral y en el funcionamiento de los sistemas políticos. Elaborando modelos y mapas de Europa, Rokkan descubre que en el caso de ciertos países europeos las divisiones entre norte y sur, este y oeste (Noruega e Italia, por ejemplo) y su relación con las diferentes configuraciones de las estructuras sociales desempeñan un rol crucial en la dinámica política. De aquí su interés por las diferencias geopolíticas internas de los países europeos, en una época en la cual la mayor parte del análisis político comparado procedía confrontando esquemas globales y sociedades nacionales.

3. La tercera idea-guía es central y se refiere a la división entre centro y periferia que hace comprensible la dimensión territorial de cada sistema político. Aquí, el concepto Vërband ${ }^{6}$ (formación) político es central, en cuanto que estudia y compara los Vërbande políticos, analiza su desarrollo y busca explicaciones de sus mutaciones y de las diferencias entre sus estructuras. En el caso noruego, los conflictos regionales entre las diversas áreas geográficas se intersectaban con los conflictos de las zonas centrales que acumulaban poderes económicos, políticos y culturales, mientras las zonas periféricas se rebelaban contra la hegemonía del centro. De tal forma, los conflictos entre los "centros" y las

6 Rokkan utiliza esencialmente el concepto de Weber: "Un Vërband de poder debe ser llamado un Vërband político, en la medida en la cual su existencia y la validez de sus ordenamientos en un territorio dado con determinados límites geográficos son garantizados continuamente mediante el empleo y la amenaza de la coerción física por parte del aparato administrativo" (Weber, Max: Wirtschaft und Gesellschaft, citado por Flora, 1980: 379). 
"periferias" y las relaciones centro-periferia hacen de esta dimensión uno de los ejes más importantes de su concepción del desarrollo político.

4. A partir del análisis del caso noruego, y de la interacción entre conflictos culturales (la resistencia de las comunidades rurales a la lengua y al estilo de vida de las ciudades) y conflictos económicos (entre los intereses contrapuestos de las clases dominantes y las clases subalternas, campesinos y propietarios, de la ciudad y del campo), Rokkan derivó la idea de la presencia contextual de dos dimensiones fundamentales del proceso político: el conflicto cultural-territorial (entre tradiciones locales y los intentos de "integración" nacional) y el conflicto económico-funcional entre intereses contrapuestos. En términos generales, la idea es que cultura y economía desarrollan un rol autónomo, aunque sí la importancia de una y otra varía según el momento histórico en el condicionamiento de los procesos políticos. De esta forma, Rokkan escapa al dilema de la oposición de la unilateralidad tanto del marxismo y el idealismo o, en términos del debate sociológico de aquellos años, al dilema Marx-Parsons.

5. A partir de la modelación de estas ideas-guía, Rokkan formuló una serie de hipótesis que puso a prueba en los sucesivos análisis comparados sobre Europa. De allí derivó el argumento de que los conflictos decisivos que han forjado la política contemporánea en los países europeos se verificaron antes del ingreso en la escena política de la clase trabajadora (que en el caso de América Latina era una idea dominante por la influencia del marxismo). Rokkan no sólo encontró en el caso noruego, sino en casi todos los países europeos, que los sistemas de fracturas sociales y las divisiones políticas que explican las diferencias entre los diversos sistemas de partidos se afirmaron mucho antes de que la industrialización produjera la movilización política de la clase obrera. Si bien esta última dio lugar en toda Europa a la formación de partidos socialistas y a las organizaciones sindicales, contribuyó también a uniformar el variado panorama político europeo. Sin embargo, las notables diferencias entre los sistemas políticos permanecieron y éstas se formaron mucho antes que el surgimiento de los partidos socialistas. En este sentido, Rokkan se movió a contracorriente en un periodo en el cual la historiografía política y social interpretaba la industrialización y la consecuente movilización obrera como el parte aguas entre dos épocas, y la ciencia política, bajo la influencia determinante de Maurice Duverger, consideraba el nacimiento de los movimientos socialistas como un evento decisivo del desarrollo político europeo (Panebianco, 1982: 15).

\section{EL MACROMODELO DEL DESARROLLO POLÍTICO EUROPEO}

En los años setenta, Rokkan se interesó en las variaciones del desarrollo político europeo y no sólo en las uniformidades y diferencias en el proceso de democratización. Desarrolló una "familia de modelos para la historia comparada de Europa", que a la larga se convirtieron en conjunto en un macromodelo. La aparición de la obra de A.O. Hirschman Exit, Voice and Loyalty incidió significativamente en el pensamiento de Rokkan orientándolo hacia nuevas interrogantes y nuevos problemas de investigación. Hirschman (1977) elaboró una teoría para explicar cómo las sociedades, las empresas y organismos pueden sobrevivir pese al deterioro 
interno. ¿Cómo el comportamiento antifuncional de ciertos actores no es lo suficientemente poderoso para conducir a sociedades o empresas a un deterioro general? Hirschman señala que en situaciones de competencia normal (no perfecta) existen dos mecanismos o fuerzas endógenas que ponen en alerta a los sistemas en cuestión sobre su posible decaimiento: la salida (exit), típico de los sistemas económicos, y la voz (voice), de los sistemas políticos. La salida es el mecanismo que los clientes utilizan en el mercado en la búsqueda de bienestar y/o para mejorar su posición, pero también es parte del funcionamiento de los mecanismos del mercado. Ante el deterioro de una empresa u organismo y sus productos, los clientes pueden optar por otra alternativa; la salida es un mecanismo claro e impersonal del cual sus efectos se pueden conocer por las estadísticas que genere el organismo en cuestión. La empresa puede reaccionar para mejorar su desempeño, de lo contrario la salida de sus clientes la llevaría a la desaparición. La voz es una opción opuesta a la salida y no puede medirse claramente, pero sí puede graduarse: desde un débil murmullo hasta una violenta protesta. "La voz es una acción política por excelencia". Significa un intento por cambiar un estado de cosas poco satisfactorio, en lugar de abandonarlo (exit) mediante la petición individual o colectiva hacia los responsables o autoridades. La voz tiene la intención de forzar al cambio ante la percepción del deterioro, y sólo puede restringirse cuando la salida no es una opción libre. Ante la voz, los dirigentes de los organismos pueden aplicar la expulsión de los miembros que optan por ella como una forma de tratar de mantener el equilibrio al interior. Por otro lado está la lealtad, que no es exactamente una alternativa a las opciones de la salida y la voz, sino más bien un mecanismo que, dependiendo de su intensidad, reduce la opción de salida y fortalece la voz. Cuando un miembro se siente preocupado por el deterioro y considera que tiene la capacidad de influir para mejorar al organismo, tiende a fortalecer los mecanismos de la voz y a levantar la barrera de la salida, es decir, a permanecer fiel hasta cierto límite. La lealtad implica que los individuos se sienten apegados a la empresa, al organismo o a los productos, y prefieren encauzar sus esfuerzos en la búsqueda de la mejoría antes que optar por la salida.

La teoría de Hirschman encamina a Rokkan hacia la investigación: i) sobre los procesos conexos a la construcción de los confines mediante el control de las "entradas" y las "salidas", y la consolidación de las "lealtades" hacia las naciones en la formación de los Estados territoriales y de las naciones europeas; ii) sobre las tensiones conexas a la contemporánea presencia de fuerzas que definen y/o estabilizan los confines (es decir, los principios, las burocracias centrales, las lenguas nacionales) y las fuerzas que las trascienden (es decir, las iglesias, los flujos comerciales, el latín como lengua culta transnacional); y iii) sobre la interdependencia entre el control de salida a través de los confines territoriales y nacionales y el control de la voz al interior de los confines. En el modelo permanecen firmes varios de los resultados de sus investigaciones precedentes, en especial el rol de las divisiones centro-periferia y la dialéctica entre conflictos culturales-territoriales y económico-funcionales. Al mismo tiempo, se acompaña de un uso nuevo del modelo AGIL de T. Parsons, para dar cuenta del pasaje de las comunidades primordiales a las más amplias y complejas agregaciones territoriales.

Parsons (1968: 8-116) propone el modelo como instrumento de análisis de una sociedad, y en general para cualquier sistema social. La clave de lectura es que todo sistema para 
sobrevivir y desarrollarse debe resolver cuatro problemas funcionales: (A) Adaptación: todo sistema debe satisfacer las exigencias situacionales externas: adaptarse a su entorno y adaptar el entorno a sus necesidades; (G) Goal attainment o capacidad para alcanzar metas: todo sistema debe definir y alcanzar sus metas primordiales; (I) Integración: todo sistema debe regular la interrelación entre sus partes constituyentes y controlar al mismo tiempo la relación entre los otros imperativos funcionales; y (L) Latencia o mantenimiento de patrones: todo sistema debe proporcionar, mantener y renovar la motivación de los individuos y las pautas culturales que crean y mantienen la pertenencia. Combinando el esquema salida-voz-lealtad de Hirschman y la teoría de la diferenciación de T. Parsons (inicialmente llamándolo asimismo Modelo Hirschman-Parsons) genera un esquema interpretativo de partida para examinar los procesos de construcción del Estado y de la nación en Europa. Utilizando el esquema de Parsons, Rokkan señala cuatro fundamentales procesos de diferenciación estructural: i) político-militar; ii) económico-tecnológico; iii) cultural; y iv) las instituciones jurídicas. Este esquema (Figura 1) introduce por tanto cuatro componentes primarios: Fuerza, Economía,

FIGURA 1

Esquema fundamental

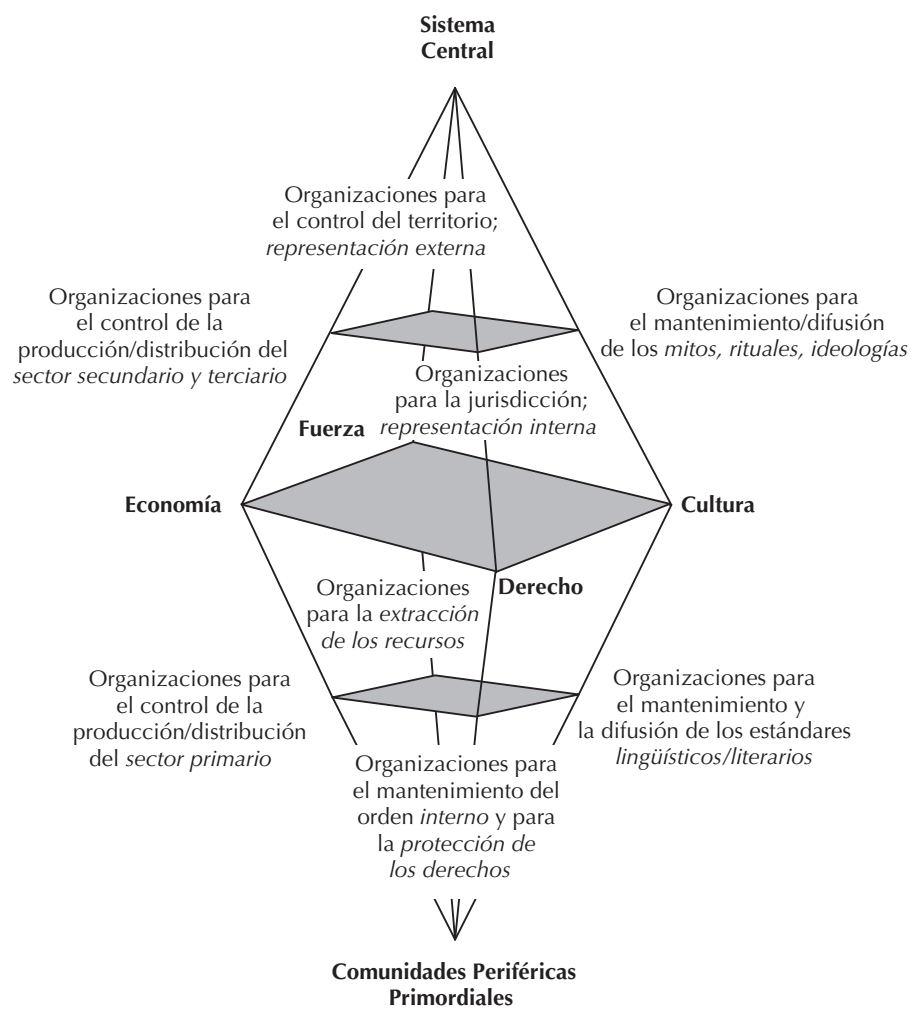


Cultura y Derecho, que se interrelacionan con la distinción centro-periferia, obteniendo así un esquema tridimensional que representará el modelo analítico de base del desarrollo político europeo (Rokkan, 2002: 133-136):

"Cada uno de los polos del campo bidimensionales intersecta el eje centro-periferia, correspondiendo a un conjunto de prerrequisitos funcionales para el desarrollo y mantenimiento de un sistema territorial: debe existir cualquier forma de organización para la protección de los confines mediante el uso de la Fuerza, debe existir un cierto grado de aceptación de una Cultura común que sea expresada en términos lingüísticos o religiosos, o ambos; deben existir algunos estándares mínimos para la resolución de las disputas y para el control de conductas desviadas mediante el Derecho; $y$ todas estas organizaciones para el mantenimiento de los confines externos y del orden interno dependen para su sobrevivencia de cualquier forma de compromiso con los agentes de la Economía. Sin embargo, dichos prerrequisitos no pueden ser todos establecidos y reforzados al mismo tiempo, por lo que podemos identificar las 'fases temporales' en los conflictos relacionados con la creación y el reforzamiento de cada uno de estos prerrequisitos y podemos identificar 'secuencias de crisis' en cada una de estas cuestiones" (Rokkan, 2002: 175).

El modelo identifica una serie de Master Variables que corresponden a una serie de cuestiones principales, las cuales ayudarán a comprender las microvariaciones: i) las características de las periferias "dominadas" y su capacidad de resistencia (voice), es decir, en qué medida dependen del centro y cómo son integradas en el sistema o cuán fuerte es su resistencia e independencia (exit); ii) las características del centro, es decir, qué alianzas dominan en el sistema, cuán grandes son las diferencias entre los diversos sectores de la élite, qué conflictos existen entre ellos y de cuáles recursos internos y/o externos disponen (exit); y por último iii) los procesos de mutación en las relaciones centro-periferia, sobre las modalidades del desarrollo de las comunidades nacionales (loyalty). El modelo se conjuga preliminarmente con cuatro procesos fundamentales de "formación del sistema", los dos primeros se refieren al centro, y los otros dos parten de la periferia: i) formación del Estado en estricto sentido: procesos de integración política, económica y cultural al nivel de la élite; desarrollo de las organizaciones para la movilización de los recursos, la defensa de las fronteras y el mantenimiento del orden interno; ii) formación de la nación: procesos que refuerzan los contactos entre las élites del centro y los sectores más alejados de la población periférica (escuelas, servicio militar, medios de transporte, etc.), y por lo tanto contribuyen a una estandarización cultural y a una extensión de la conciencia de la identidad nacional; iii) participación: procesos de creciente participación política activa por parte de sectores más amplios de la población que impulsan la institucionalización y la adecuación de los derechos civiles de libertad y los derechos políticos de participación, y llevan a la creación de partidos políticos -ciudadanía política- (véase Rokkan, 1966); y iv) redistribución: procesos de ulterior expansión del aparato estatal a través de la extensión de los servicios sociales así como los intentos de equiparación de las condiciones económicas entre grupos de población y regiones mediante la fiscalización progresiva y el pago público de transferencias -ciudadanía social- (Flora, 1980: 390-391). Sobre estas bases, Rokkan construye su "Mapa geopolítico de Europa" o, como él lo Ilama, un "Modelo topológicotipológico" (Figura 2) que cubre toda la historia de Europa occidental y tiene el objetivo 


\section{FIGURA 2}

Un modelo de Europa

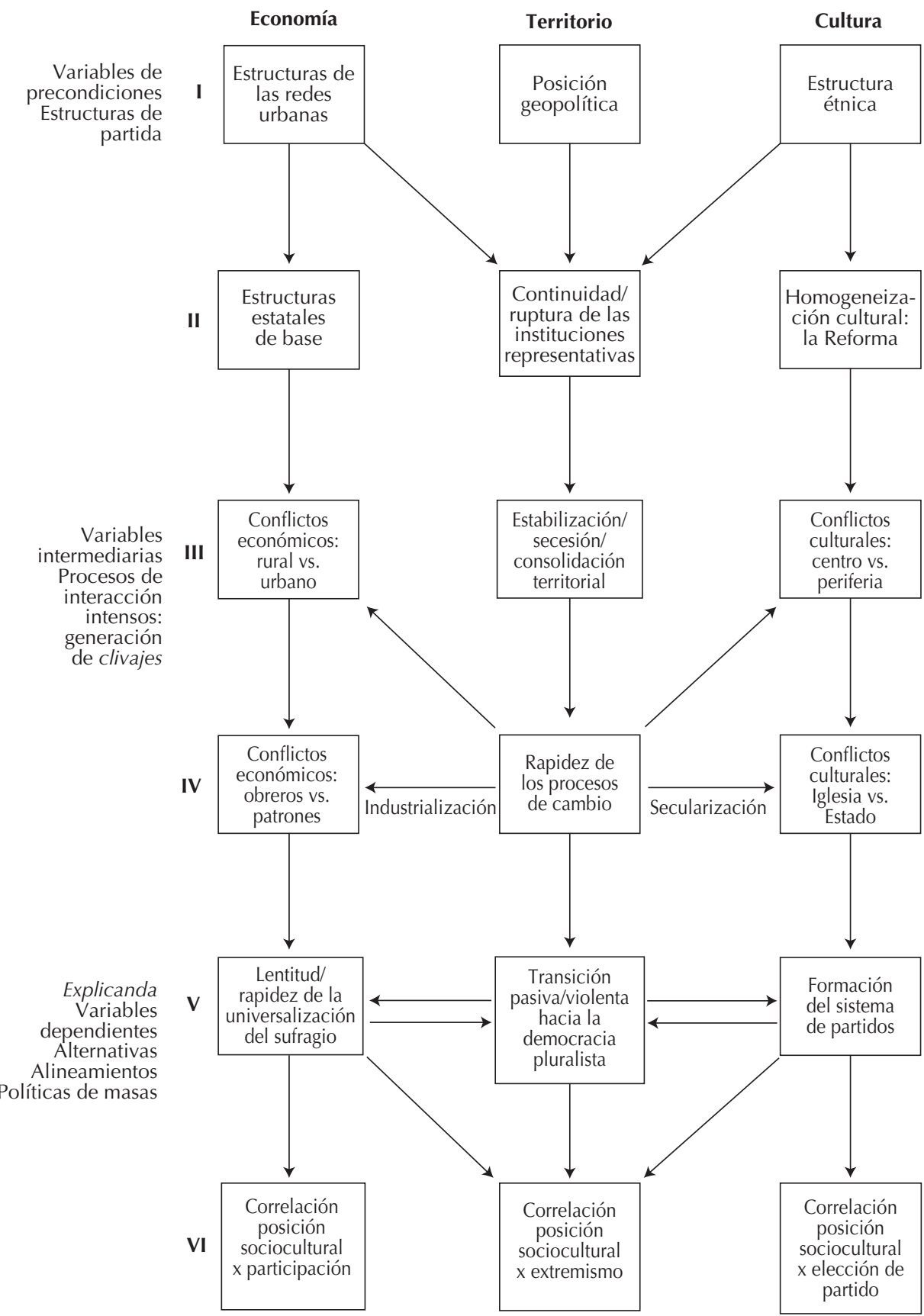


de dar cuenta de las variaciones de los procesos de construcción del Estado, de la nación, y las dinámicas posteriores de democratización.

El mapa representa un esfuerzo intelectual por identificar las variables cruciales en el largo y complejo proceso que llevó a la conformación de los sistemas territoriales, económicos y de los alineamientos políticos en la Europa del siglo XX. Como señala el mismo Rokkan:

“No es posible explicar las marcadas variaciones en la estructuración de la política de masas en Europa occidental sin observar muy atrás en la historia, sin analizar las diferencias en las condiciones iniciales de los primeros procesos de organización territorial, de construcción del Estado y de concentración de los recursos" (Rokkan, 2002: 182).

El mapa se remonta a la caída del Imperio Romano de occidente y la larga secuencia de cambios que sufren los territorios europeos, fragmentaciones y unificaciones hasta la construcción de las instituciones del Estado moderno. Los elementos principales expuestos en la Figura 2 se reagrupan por periodos y tipos. El reagrupamiento por periodos reproduce un diseño analítico de base: un conjunto de variables de precondiciones (I, II); de un conjunto de variables de procesos intervinientes (III, IV); y por último, un conjunto de explicanda (V, VI). Las variables de precondiciones e intervinientes son reclasificadas por tipos, esencialmente económicas, territoriales y culturales. Al nivel de las variables de explicanda opera una distinción entre las variables que caracterizan la extensión de los derechos de participación y las variables que describen el conjunto de alternativas para la política de masas, ya sean a nivel sistémico como a nivel de partidos. Cada una de las variables está indicada a través de una serie de palabras clave: la explicación plena de cada una lleva al mismo tiempo a los límites de su enunciación. De allí el poder heurístico del mapa. El conjunto de variables de precondiciones constituyen la plataforma para el estudio de todas las variables de los procesos intervinientes en el modelo: son aspectos esenciales para cualquier tipo de análisis de la generación de fuentes de fracturas (clivajes) durante el siglo y medio que sigue después de la Revolución Francesa. Esta última puso las bases para una vasta gama de procesos de centralización, de consolidación territorial y de autoafirmación nacional. La Revolución Industrial generó contrastes incluso más fuertes entre territorios centrales económicamente prósperos y las provincias periféricas estancadas. La interacción entre estas dos revoluciones paralelas generó variaciones complejas a nivel de las estructuras de fracturas, las cuales, a su vez, produjeron marcadas diferencias en el estilo y en la estructura de la política de movilización de masas en Europa occidental. El conjunto de variables de procesos intervinientes constituyen la plataforma para el análisis de los explicanda, es decir, las variaciones en las estructuras de respuesta política. El modelo especifica dos fases y tres sectores de variación. Los aspectos relativos a la estructuración de las alternativas políticas responden a las cuestiones: ¿cuáles tipos de opciones se presentaron a los grupos de masas emergentes? ¿Cuán estables o cuán vulnerables fueron estas alternativas en realidad? En la dimensión de los alineamientos de masas se ubican los aspectos cruciales de cada sistema territorial respondiendo a: el peso de la pertenencia étnica/religiosa/cultural, las diferencias entre las clases y los sectores ascendentes y aquellos estancados, entre las viejas y nuevas clases medias, así como entre campesinos y trabajadores industriales. El modelo reduce la 
gran complejidad de las diversas historias territoriales a una serie de conjuntos de variables concatenadas en el tiempo.

Las variables pueden ser utilizadas para caracterizar las unidades en diversos niveles de complejidad. No es el objetivo de este trabajo el de mostrar todos los aspectos de la sistematización del modelo que elabora Rokkan. Como él mismo señala (2002: 186), lo relevante es el carácter multidimensional del modelo: en cada fase se atribuye un peso a las dimensiones económico-tecnológicas, político-territoriales y cultural-étnica-religiosas. El modelo enfatiza las precondiciones políticas y culturales que surgieron de los grandes cambios económicos de los siglos XV y XVI, y que tuvieron impacto en la organización territorial y en las estructuras de identidad cultural en los sucesivos procesos de cambio en la economía mundial. La tarea principal de una macrohistoria sistemática es el análisis de las dinámicas de interacciones entre sistemas económicos, políticos y culturales: cada sistema posee un ritmo y confines específicos, pero el destino de cada territorio y de sus instituciones es determinado por los procesos de interacción entre sistemas a través de sus confines. El modelo conlleva al análisis de la generación de fracturas en la interacción de tres procesos fundamentales de cambio entre 1789 y 1815: la revolución geopolítica que se expresa en la secesión y en la consolidación de los territorios; la revolución económica, que se expresa en la expansión capitalista y en la industrialización; y por último, la revolución nacional que se expresa en las oposiciones por parte de minorías periféricas y/o en los conflictos Estado-Iglesia. Así también el modelo conlleva al estudio de las variables para la estructuración de las alternativas políticas, en particular las fases de ampliación del sufragio y la génesis de los sistemas de partidos, que es la base del siguiente apartado.

\section{LA TEORÍA DE LA DEMOCRATIZACIÓN Y DEL PLURALISMO}

Rokkan elaboró una serie de modelos hipotéticos con el objetivo de "poner un poco de orden intelectual" en el estudio de los procesos de democratización y de movilización partidista en la competencia electoral (Rokkan, 2002: 301). Para Rokkan, la democratización significa "el mejoramiento institucional de las oportunidades de participación política e influencia política a disposición de una población en un sistema territorial a través de la superación de cuatro umbrales: legitimación, incorporación, representación y del acceso al poder ejecutivo". Propone inicialmente una división de dos grandes cuestiones presentes en todos los procesos de democratización: primero: las variaciones y cambios de las "reglas del juego" institucionales dentro de un determinado sistema político, lo cual configura un sistema de respuestas, es decir, los outputs de la reorganización institucional de frente a las presiones hacia el sistema (presiones desde abajo o externas); y segundo: las variaciones y cambios organizacionales, a saber, de "las oportunidades determinadas por factores culturales, sociales y económicos para la articulación de la protesta, para la agregación de las reivindicaciones y para la movilización de bases de apoyo", lo cual configura las fuentes de inputs, es decir, el mercado político de la movilización de apoyos para reivindicaciones particulares y para presiones sobre el sistema decisional, fuentes que pueden ser ampliamente agregadas o precisamente articuladas. 
El objetivo final es evaluar los procesos de interacción entre outputs e inputs, para definir con precisión las consecuencias para nuevos outputs y ulteriores inputs; y el impacto de nuevos inputs sobre la gama de opciones para los decisores políticos y para la generación de nuevos outputs. Para ello Rokkan construye dos tipologías: una para los outputs, es decir, las variaciones institucionales; y otra para los inputs, o las variaciones organizativas. Utilizando el modelo de salida y voz de Hirschman, delimita las variaciones de las condiciones para la salida con el objetivo de comprender las variaciones de la voz. La serie de tipologías que Rokkan construye a partir de estas premisas constituye un modelo teórico sobre el desarrollo de la democracia y el pluralismo político, el cual explica las "fases críticas del desarrollo y de la estructuración de la política competitiva de masas" en los países de Europa occidental. Rokkan (2002: 301 y passim) elige la perspectiva comparativa diacrónica respecto de la sincrónica (que refiere diferencias entre casos en un mismo periodo de tiempo) porque permite describir las diferencias cruciales, país por país, respecto a "las secuencias en la adopción de las reglas de juego electoral y la formación de las alternativas partidistas". Los límites del modelo van terminus a quo el conflicto sobre las identidades cultural-religiosas de los Estados-nación que emergen en el siglo XVI; y terminus a quem la introducción de la democracia electoral universal e igual, y el "congelamiento" de las alternativas partidistas que en la mayoría de los países sucede en los años veinte y treinta del siglo XX. La teoría de la democratización y del pluralismo, propiamente dicha, de Rokkan, se divide en dos grandes modelos: i) el modelo de los cuatro umbrales institucionales (thresholds) de la democratización; y ii) el modelo de las estructuras de fracturas y de sistemas de partidos (Figura 3).

Rokkan (2002: 324) concentra su análisis en los sistemas políticos competitivos europeos (vigentes en la década de los años setenta del siglo XX) poniendo particular atención a seis "pequeñas democracias europeas", los tres países del Benelux, Irlanda, Suiza y Austria, comparándolas entre sí y con los mayores sistemas políticos de la región: Gran Bretaña, Francia, Alemania (antes Prusia), Italia y, en algunos aspectos, España. Los países que elige comparten una característica central importante: tienen una larga historia política parlamentaria competitiva; ya en los años veinte habían ampliado los derechos de ciudadanía política a todos los adultos ${ }^{7}$. Pero existían diferencias en el carácter de la competencia electoral: los conflictos sobre la representación se habían progresivamente nacionalizado a través del desarrollo de los partidos de masas, pero las reglas de la lucha electoral diferían fundamentalmente entre países mayoritarios y países proporcionales. Este es un punto central en la comparación entre las grandes y pequeñas unidades del sistema europeo occidental, en cuanto que los sistemas de representación proporcional tienden a "congelar" las primeras estructuras de articulación y agregación. Las democracias pequeñas fueron más favorables a adoptar y mantener el sistema proporcional, mientras que las democracias grandes lo han rechazado, modificado, o entraron en conflicto por las controversias sobre su mantenimiento.

Sólo a los hombres en Suiza, Francia e Italia; en Bélgica a las madres y esposas de militares; en Gran Bretaña únicamente a las mujeres de las clases altas; y en los otros países a todos sin distinción de género. 


\section{FIGURA 3}

El desarrollo de la política de masas competitiva en Europa occidental:

Los elementos de la teoría de Rokkan

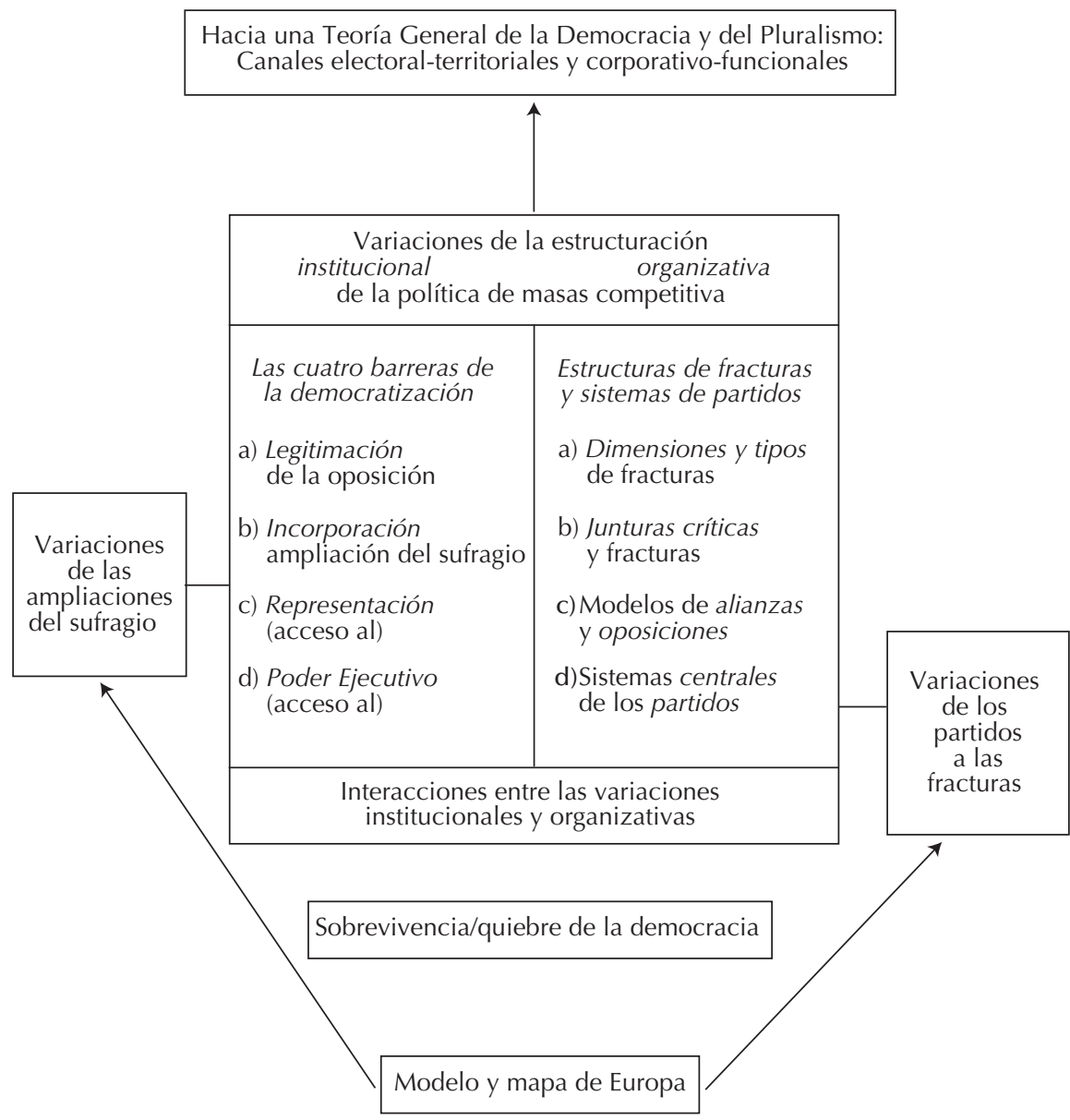

\subsection{Los cuatro umbrales institucionales de la democratización}

Para Rokkan existen una serie de secuencias en el proceso de democratización y movilización de las masas: cualquier movimiento político emergente pasa por un sistema de "umbrales" ${ }^{8}$ o barreras (thresholds) durante el curso hacia el centro del sistema político y hacia lo alto en la arena central de decisión. Así, el proceso de democratización en Europa estuvo signado por el pasaje del absolutismo a la democracia a través de la superación de cuatro umbrales.

8 Rokkan toma la idea de Lewis Namier quien "comparó una vez las elecciones con las esclusas de un canal: éstas permiten a las fuerzas socioculturales emergentes correr a través de los canales de un sistema, pero también permiten frenar las ondas y detener el flujo" (Rokkan, 2002: 325). 
El primero, el umbral de la legitimación, que responde a una serie de preguntas tales como: ¿en qué momento en la historia de la formación del Estado y la construcción de la nación se introduce el reconocimiento efectivo del derecho de petición, de crítica, de manifestación contra el gobierno?, lo que permite identificar los momentos en los que se legitima la existencia de la oposición política con derechos de crítica y petición.

El segundo, el umbral de la incorporación, responde a: ¿cuánto tiempo pasó antes que las bases potenciales de los movimientos emergentes de oposición recibieran los derechos formales de participación en la designación de representantes a la par de los grupos, clases, estamentos o sectores ya afirmados?, lo que permite encontrar los momentos en los cuales la oposición obtiene derechos políticos, de asociación y electorales.

El tercero, el umbral de la representación: ¿cuán altas eran, en su origen, las barreras para permitir la representación de nuevos movimientos?, y ¿cuándo y cómo fueron reducidas para permitir a estos movimientos obtener más fácilmente escaños parlamentarios? Es decir, identificar el momento en el cual la oposición puede proponer y elegir a sus representantes para el parlamento.

El cuarto es el umbral del poder ejecutivo: ¿hasta qué punto eran los órganos del ejecutivo inmunes a las presiones del legislativo?, ¿cuánto tiempo pasó antes que la fuerza parlamentaria se tradujera en influencia directa sobre las decisiones del ejecutivo?, ¿cuándo la oposición pudo acceder legítimamente a los cargos en el ejecutivo? Es decir, observar cuándo es legal y legítimamente posible, por un lado, la presión del legislativo hacia el ejecutivo, y por otro, la conquista del gobierno por parte de la oposición (Rokkan, 2002: 326-328).

Los dos primeros umbrales (o barreras) controlan el desarrollo de la política de masas competitiva. Una vez reducida la barrera de la legitimación, se presenta un cambio significativo en el carácter de la política: los conflictos entre las élites y las medidas represivas contra la disidencia son progresivamente sustituidas por el debate público y por la competencia abierta por la búsqueda de apoyos. Una vez reducida la barrera del sufragio, y el público potencial del debate y del mercado de la competencia aumentan considerablemente, el resultado será casi invariablemente una carrera de la organización para el reclutamiento de bases y por la consolidación de las identidades políticas. Empíricamente, los cambios que suceden en un umbral generan, tarde o temprano, presiones para el cambio en el otro, pero el momento de estas decisiones varía fuertemente entre sistemas políticos. Rokkan señala que para comprender mejor las fuentes de tales cambios -en el caso europeo- se deben analizar también las secuencias de la formación del Estado y la construcción institucional en cada sistema político (Rokkan, 1980), ya que los puntos de partida de los procesos de democratización variaron fuertemente de caso en caso -es decir, la cuestión del timing-. Tomando en cuenta: i) el grado de avance de la consolidación territorial durante el Medioevo; ii) la continuidad en la operatividad de los órganos medievales de representación (territoriales o de clases); iii) las diferenciaciones entre países ya afirmados, y aquellos recientemente independientes (secesión) poco después de la Revolución Francesa; y iv) las dimensiones y la fuerza del sistema político dominante antes de la secesión. De tal modo, Rokkan elabora una tipología para la clasificación de los sistemas políticos europeos del siglo XX según las 
condiciones iniciales de su desarrollo democrático, más específicamente un mapa de las "variaciones de la extensión del sufragio en Europa de acuerdo al tipo de tradiciones de gobierno heredadas" (Rokkan, 2002: 332-333).

De las diferenciaciones que encuentra genera al menos cuatro generalizaciones (hipótesis) de los efectos del proceso de democratización: i) las posibilidades de una legitimación precoz de las oposiciones serán mayores allí donde las tradiciones heredadas del régimen representativo por clases, por asambleas territoriales o por consejos de pueblos sean más fuertes; ii) las barreras a la legitimación en un territorio dependiente serán más altas y, por consecuencia, los riesgos de violencia en el plano interno de la política del Estado-nación que se independiza serán más elevados si el status internacional del país dominante es más alto; iii) el proceso de ampliación e igualación del sufragio será más lento, pero también más difícil de revertir, allí donde las tradiciones heredadas del régimen representativo son más fuertes; y iv) las fases en el proceso de democratización serán menores allí donde la amenaza para las aspiraciones de independencia nacional es más visible, independientemente de las tradiciones de representación.

Las dos primeras hipótesis -señala Rokkan-son difíciles de verificar, no obstante es posible describir detalladamente las secuencias de las decisiones legislativas y ministeriales sobre la libertad de expresión y sobre los derechos de asociación, aunque es más complicado conocer los efectos reales de tales medidas. Por otro lado, las dos últimas hipótesis sobre el proceso de ampliación e igualación del sufragio se prestan más fácilmente a la verificación empírica, pues la sucesión de leyes electorales pueden ser codificadas en diversas dimensiones. Los dos primeros umbrales colocaron las bases para el surgimiento de la política de masas competitiva, ya que una vez superadas dichas barreras un sistema político entra en la era de la ingeniería electoral y organizativa de masas. Pero ello no significa arribar a una dinámica de uniformidad de las estructuras de la política electoral: las reglas del juego variarán con las reglas de la representación y las reglas de acceso al poder ejecutivo. El umbral de la representación estuvo bajo fuertes presiones -afirma Rokkan- una vez que los derechos de participación política se extendieron a todos o a la mayor parte de los ciudadanos masculinos: los partidos emergentes de masas, hasta ese momento excluidos, protestaron contra las injusticias numéricas de los sistemas de mayoría relativa; los partidos más pequeños, entre los cuales estaban los del régimen censatario, se atrincheraron y temían por su propia sobrevivencia y encontraron más conveniente reducir la barrera de acceso a la representación parlamentaria antes que fundirse con el partido dominante contra los nuevos pretendientes al poder.

Siguiendo las ideas de G. Sartori sobre los sistemas electorales, las opciones a favor de la representación proporcional podrían caracterizarse como "la estrategia del más débil": en las pequeñas democracias los líderes cedieron a las presiones para reducir la barrera de la representación porque prefirieron la seguridad de sus propias posiciones ya afirmadas frente a la incertidumbre de las elecciones de mayoría relativa donde "el vencedor se lleva todo". Este punto es de crucial importancia en el estudio comparado de los sistemas de partidos. La introducción de la representación proporcional en la fase final de la movilización de 
masas condujo a la estabilización de las estructuras partidistas en las regiones centrales y más diferenciadas de cada país. Rokkan señala que los sistemas de partidos de los años sesenta del siglo XX "reflejaban, con pocas pero significativas excepciones, los sistemas de fracturas de los años veinte". La característica crucial de la política competitiva occidental en una época de "elevado consumo de masas" es que las alternativas partidistas y, en un número sorprendentemente elevado, las organizaciones partidistas (eran) más remotas que la mayoría de los electorados nacionales. Este "desvío organizativo" es una hipótesis en la investigación comparada sobre los procesos electorales contemporáneos: no sólo es necesaria la información sobre los procesos de cambio socioeconómicos, sino también sobre la edad y la estabilidad de las alternativas partidistas.

Pero, una vez superados los tres primeros umbrales, ¿cuántos votos, cuántos escaños son necesarios para que los partidos que ingresan a la arena de la competencia tengan la posibilidad de ejercitar una efectiva influencia sobre las decisiones centrales del sistema político? En este sentido, las hipótesis son: las posibilidades de participación de las minorías en el poder ejecutivo parecen aumentar cuando i) disminuye la distancia del partido más grande del punto de mayoría; ii) con la cercanía y la capacidad "negociadora" de las alternativas políticas con potencial de coalición, y iii) con el aumento de las presiones del sistema internacional. En la elaboración de estas hipótesis y generalidades a partir del caso europeo, Rokkan encontró notables diferencias entre los países tanto en tiempo como en el devenir de las fases propuestas. En algunos países las elecciones tuvieron el carácter de alternativa efectiva entre las diversas opciones de partidos al gobierno; pero en otros, sirvieron simplemente para expresar lealtades segmentadas y para asegurar su derecho a una cierta representación, aun cuando se trató de un solo cargo en los resultantes gobiernos de coalición.

\subsection{Estructuras de fracturas y sistemas de partidos}

Para Rokkan (2002: 345) los sistemas políticos modernos varían extraordinariamente en el modo en el cual el voto del electorado es considerado en las decisiones nacionales, y pueden ser analizados en dos perspectivas: desde la ciudadanía de masas, y desde los grupos corporativos que controlan los recursos en un sistema. Al nivel de las masas, existe una igualdad formal en el electorado, definido a través de criterios territoriales: en cada distrito o colegio, un voto cuenta tanto como cualquier otro y las decisiones se toman a través de cualquier forma de agregación. Al nivel corporativo no existe igualdad: puede existir como una forma de procedimiento a favor de la paridad en la organización de arenas para la negociación, pero aquello que es importante es la capacidad de movilización, de control y, en particular, de sustraer recursos de importancia directa para el mantenimiento del sistema político territorial. Pero las diferenciaciones tienen raíces más profundas y éstas se encuentran en: i) los tipos de fracturas (clivajes) y su "politización" durante el proceso de democratización; ii) las junturas críticas como orígenes históricos de las fracturas y su traducción en partidos en un proceso de construcción de alianzas y oposiciones; así como iii) el nacimiento de los diversos tipos de partidos. Las diferencias originarias de los sistemas de partidos están en el sistema de fracturas, las cuales fueron producto de los procesos de formación del Estado y la construcción de la nación. Las fracturas o clivajes son conflictos 
particularmente fuertes y prolongados que radican en la estructura social. Para Rokkan las estructuras de fracturas existían mucho antes del nacimiento del sistema de partidos, pero "sólo después de la introducción y la extensión del sufragio las fracturas ya existentes vienen transformadas en sistemas de partidos embrionales"; por ello es un proceso y una correspondencia de características estructurales conectadas a través de un modelo de formación de alianzas y oposiciones. Una "estructura de fractura" es un nexo conceptual entre estructuras sociales y sistema político, entre estructuración y construcción de confines; relaciona ambos elementos y es dinámico, en cuanto que interpreta las estructuras de fracturas como el producto de procesos y de los problemas del desarrollo. Para identificar un sistema de fracturas es necesario preguntarse: ¿cuáles fracturas se presentaron inicialmente influenciando la forma y el significado de las fracturas sucesivas? (timing); ¿cuáles fracturas deben considerarse dominantes o secundarias en términos de intensidad y duración? (jerarquía); y ¿cuáles fracturas coincidieron, reforzándose entre sí, y cuáles se intersectaron creando complicadas posiciones mixtas? (intersección). Los sistemas de fracturas tienen al menos dos dimensiones: i) territorial, que genera el eje de las relaciones centro-periferia; y ii) funcional, que genera el eje económico y cultural. En el desarrollo de los sistemas políticos las fracturas emergen cuando se presentan junturas críticas, las cuales son periodos de cambio radical y pueden asumir formas diversas: de duración limitada, como guerras civiles; o cambios estructurales de largo alcance. Las fracturas después se congelan por largos periodos de tiempo. En el corazón del análisis de Rokkan encontramos cuatro tipos fundamentales de fracturas, producto de las dos mayores revoluciones del "largo siglo XIX": la Revolución Francesa (I, II) y la Revolución Industrial (III, IV).

I) Fractura Centro-Periferia, es el conflicto entre la cultura del centro constructor de la nación y las poblaciones sometidas de las provincias y las periferias distintas étnica y lingüísticamente, que ven su cultura amenazada por los intentos de centralización y estandarización por las élites centrales nacionales y su aparato burocrático; II) Fractura Estado-Iglesia, es el conflicto entre las aspiraciones del Estado-nación centralizador, "estandarizador" y movilizador, y de las reivindicaciones corporativas de la Iglesia, sobre todo respecto al control de la educación. El origen de estas dos fracturas se encuentra en los "procesos tempranos" de formación del Estado y en las variaciones de las relaciones Estado-Iglesia en la Reforma (siglos XVI-XVII). Pero las reivindicaciones del Estado-nación, soberanía popular, lealtad suprema y conformación de la cultura y el territorio son un fenómeno moderno que se inició con la Revolución Francesa.

A dos fracturas de origen remoto se suman dos nuevas fracturas producto de la Revolución Industrial en el curso del siglo XIX: III) Fractura Urbano-Rural, son los conflictos entre las zonas rurales y las áreas urbanas generados por el crecimiento del comercio mundial y la producción industrial; es decir, los intereses agrícolas y las clases emergentes de burguesías comerciales e industriales (mercado de bienes); IV) Fractura de Clase, entre obreros y burgueses en el más claro significado marxista; fue un conflicto entre las masas emergentes de asalariados y los grupos de propietarios de los medios de producción. El carácter de la fractura urbano-rural se formó originariamente en los sistemas de propiedad territorial que emergieron antes de la Revolución Industrial y de las relaciones urbano-rurales preindustriales más antiguas. Por otro lado, la fractura de clase se cernió por el conflicto entre internacionalismo proletario 
y el socialismo que acoge a la nación, conexo con una juntura crítica: la Revolución Rusa y sus efectos en el sistema internacional.

La materialización de dichas fracturas en partidos no fue automática, fue necesaria la intervención de elementos institucionales (los umbrales de la democratización), y su presencia o ausencia facilitó o dificultó la formación de alianzas políticas y por lo tanto la traducción del sistema de fracturas (clivajes) en sistemas de partidos, algunos con ciertas uniformidades, pero también con muchas diferencias en los sistemas de alianzas y oposiciones (Panebianco, 1982: 22). La última fractura, de clase, tuvo un efecto homologador en los sistemas políticos europeos, dio vida alrededor de Europa a los partidos socialistas y dio origen a los movimientos sindicales, y facilitó la distinción ideológica en la clásica división izquierda-derecha. Las otras tres fracturas, al contrario, habiéndose manifestado antes de la fractura de clase, operaron con variaciones entre los casos. La fractura urbano-rural estuvo en el origen de la formación de los partidos agrarios sólo en los países escandinavos, donde el abismo entre los intereses industriales urbanos y los territoriales rurales en el proceso de industrialización no pudo ser contenido en un solo movimiento político -como sí sucedió posteriormente en Gran Bretaña-, y donde contemporáneamente no se formaron distintos partidos confesionales en los cuales las zonas rurales pudiesen reconocerse y confluir. La fractura Estado-Iglesia, a su vez, estuvo en el origen de los partidos confesionales sólo en los territorios de la Contrarreforma, donde más fuertes fueron las tensiones entre la Iglesia Católica y las élites liberales que construían la nación, asimismo como en las zonas limítrofes entre los territorios de la Reforma y de la Contrarreforma -Holanda y Alemania-, de confesión protestante y católica. En los territorios de la Reforma, al contrario, las Iglesias nacionales cooperaban con el "centro" político en la construcción de la nación y no se desarrollaron conflictos sobre el control de las instituciones que en otros países fueron el origen de la movilización política confesional. Por último, la fractura centro-periferia de carácter sociocultural se manifestó con grandes variaciones en Europa, dependiendo la estratificación étnico-lingüística de cada país de la consistencia de las minorías y de los recursos organizativos que el centro y la periferia podían respectivamente poner en juego en el conflicto.

\section{A MANERA DE CONCLUSIÓN: LAS PERSPECTIVAS DE ANÁLISIS PARA AMÉRICA LATINA}

La herencia intelectual de S. Rokkan materializada en sus investigaciones y el desarrollo de sus modelos conforman una teoría política en todos los sentidos, una teoría desde y para la ciencia política principalmente, hasta ahora poco estudiada en el ámbito iberoamericano. En el desarrollo de su teoría se encuentra una combinación estructurada de las tradiciones sociológicas más arraigadas: Marx, Weber y Durkheim. ¿Es una teoría estrictamente europea? Como ha señalado el más importante estudioso de su obra, Peter Flora, no queda duda de que en sus textos existen elementos que no pueden sustraerse del contexto histórico europeo, por ejemplo su modelo geoeconómico y cultural de la Europa que va del siglo XVI al XVII, además de que privilegió la formación de modelos específicos por región sólo en el ámbito europeo. Pero también es cierto, como dice el mismo Flora (1980), que su macromodelo 
parte inicialmente de preguntas generales y desarrolla por tanto conceptos generales. La obra de Rokkan incluye variables sobre procesos histórico-políticos de amplio alcance, bajo el principio de que tales variables puedan ser controladas con el auxilio de indicadores formados por series temporales. En la multidimensionalidad de los modelos, los sistemas -político, económico y cultural-son relativamente autónomos, lo que determina su influencia e interdependencia con las dinámicas interactivas que se presentan dentro del ritmo de la historia. Los elementos de la teoría de la democratización y el pluralismo no son deterministas en ningún sentido, son un corpus de variables que permiten la comparación de estructuras de sistemas políticos diferentes al caso europeo. Se trata claramente de una "teoría política" porque con ellos se genera una explicación de la variación de tres grandes procesos: la expansión del derecho al voto, el nacimiento de los partidos políticos y el desarrollo de la política competitiva por los espacios de poder político.

¿Cuáles son las perspectivas de análisis de la teoría del desarrollo político europeo de Rokkan para comprender los procesos del desarrollo político latinoamericano? En qué medida es sensato comenzar un análisis de los sistemas políticos no europeos (o extraeuropeos) bajo la perspectiva de la teoría de Rokkan depende de la evaluación inicial de los axiomas básicos de sus modelos a la luz de experiencias no europeas, contando con una serie de elementos analíticos que permitan comparar y, sobre todo, controlar las posibles hipótesis iniciales. Sin ir más lejos, es la teoría de la democratización y del pluralismo la que preliminarmente ofrece perspectivas más alentadoras para el estudio del caso "Latinoamérica". Los elementos de la teoría de Rokkan forman diversas líneas de análisis para el estudio del desarrollo político en América Latina, pero sobre todo para comprender el largo, caótico y fallido proceso de democratización en la región después de las revoluciones de independencia al inicio del siglo XIX. ¿Por qué las diversas soluciones al orden político fracasaron continuamente en casi todo el siglo XIX? ¿Por qué la democracia no se afirmó sino hasta casi finales del siglo XX? ¿Los sistemas de partidos en la región reflejan las diversas fracturas que han tenido influencia decisiva en la historia latinoamericana? ¿Por qué no obstante las grandes diferencias regionales y étnicas al interior de los Estados-nación latinoamericanos se han afirmado formas de gobierno mayoritarias como los presidencialismos? Es posible encontrar en la historia de América Latina diversas fracturas, diversas junturas críticas, así como similares modelos de alianzas y oposición dentro de los cuales emergieron los partidos políticos. Pero también habría que señalar que en Latinoamérica no sólo las dos grandes revoluciones consideradas por Rokkan tuvieron un impacto en la conformación de los actuales sistemas políticos; también la tuvieron las formas en cómo finalizaron las revoluciones de independencia, las posteriores guerras entre corrientes centralistas y federalistas, las guerras de secesión, incluso los efectos de la Revolución Cubana y la impronta de los militarismos en el siglo XX. Si bien los procesos del desarrollo político hacia la democracia tuvieron un camino diferente en la región, no fueron extraños a los procesos que se desarrollaron contemporáneamente en Europa occidental.

En suma, es posible afirmar que la teoría de Rokkan abre un extenso abanico de proposiciones para el análisis del proceso del desarrollo político en América Latina, sobre todo en la comprensión de los exitosos y los fallidos procesos de democratización una vez 
alcanzada la independencia de la península ibérica en el siglo XIX. Abre nuevas perspectivas de estudio para proponer y entender los sistemas de fracturas propias de América Latina, debiendo escudriñar en los orígenes de los Estados-nación latinoamericanos, incluso en las herencias de los siglos de los Virreinatos, así como posteriormente los efectos de los golpes de Estado en las continuas dinámicas de clausura/apertura de los umbrales de la democratización, y el desempeño de las estructuras económicas dependientes al interior y hacia el exterior de los territorios. En las ciencias sociales se corre siempre el riesgo de utilizar teorías, modelos y conceptos de forma rígida, mecánica y repetitiva. Ello ha sucedido con la teoría de los clivajes, que fue diseñada para explicar aspectos de una fase histórica determinada, y por tanto, sólo para aquella. Más aún, muchos textos que dicen tratar sobre el origen de los partidos en América Latina hablan de clivajes y el origen de los partidos de manera lineal y automática, pero nunca hablan de los procesos de congelamiento ni de las variables intervinientes para que esos clivajes a la postre "generaran" partidos. La teoría de los clivajes, como fue desarrollada por Rokkan y Lipset, no señala que tales fracturas automáticamente generen partidos. De la misma forma en que Sartori (1995) ha señalado que los sistemas electorales no tienen un efecto inmediato sobre la configuración del sistema de partidos a manera de leyes como lo había señalado Duverger, lo mismo se aplica para los clivajes. Las variables intervinientes son importantes pero casi siempre soslayadas en los análisis sobre los sistemas de partidos en América Latina. De allí que sea recomendable escudriñar sin pasividad crítica aquellos textos académicos que retoman sin consideraciones metodológicas dicha teoría, y por lo tanto no explican nada o, mejor dicho, mal explican las cosas; esta es una precaución a considerar al estudiar la totalidad de la teoría de Stein Rokkan.

\section{BIBLIOGRAFÍA}

Allardt, Erik y Henry Valen (1981): "Stein Rokkan: An intellectual profile", en Per Torsvik (comp.): Mobilization. Center-Periphery Structures and Nation-Building, Universitetsforlaget, Bergen, pp. 11-38.

Allardt, Erik y Stein Rokkan (1970): Mass Politics: Studies in Political Sociology, Free Press, New York.

Almond, Gabriel (1999): Una disciplina segmentada. Escuelas y corrientes en las ciencias políticas, Fondo de Cultura Económica, México.

Almond, Gabriel y G. Bingham Powell (1998): Politica comparata, Il Mulino, Bologna.

Almond, Gabriel, Robert Dahl et al. (2000): Diez textos básicos de la ciencia política, Ariel, Barcelona.

Bartolini, Stefano y Peter Mair (1990): Identity, Competition, and Electoral Availability. The Stabilisation of European Electorates, 1885-1985, Cambridge University Press, Cambridge.

(2000): The Political Mobilization of the European Left, 1860-1980: The Class Cleavage, Cambridge University Press, Cambridge.

Bobbio, Norberto (1981): "La teoria dello stato e del potere", en Pietro Rossi (coord.): Max Weber e I'analisi del mondo moderno, Einaudi, Torino, pp. 215-246.

Campus, Donatella y Gianfranco Pasquino (2004): Maestri della scienza politica, Il Mulino, Bologna.

Cerroni, Umberto (1979): Problemas de transición al socialismo,Grijalbo, Barcelona. 
Daalder, Hans (ed.) (1997): Comparative European Politics: The Story of a Profession, Pinter, London. (1980): "Stein Rokkan: dallo studio del caso norvegese all'analisi comparata", Rivista Italiana di Scienza Politica, 10 (3), pp. 343-364.

Dix, Robert (1989): "Cleavage Structures and Party Systems in Latin America", Comparative Political Studies, 22 (1), pp. 23-37.

Dogan, Mattei y Stein Rokkan (eds.) (1969): In Quantitative Ecological Analysis in the Social Sciences, MIT Press, Cambridge, Mass.

Flora, Peter (1980): "Il macro-modello dello sviluppo politico europeo di Stein Rokkan", Rivista Italiana di Scienza Politica, 10 (3), pp. 369-435.

Hirschman, Albert O. (1977): Salida, voz y lealtad, Fondo de Cultura Económica, México.

Marshall, Thomas (1998): Ciudadanía y clase social, Alianza, Madrid.

Mjøset, Lars (2000): “Stein Rokkan's Thick Comparisons", Acta sociologica, 43 (4), pp. 381-397.

Moreno, Alejandro (1999): Political Cleavages. Issues, Parties and the Consolidation of Democracy, Westview Press, Boulder.

Morlino, Leonardo (1980): Come cambiano i regimi politici, Franco Angeli, Milano.

North, Douglass C. (1994): Istituzioni, cambiamento istituzionale, evoluzione dell'economia, II Mulino, Bologna.

Panebianco, Angelo (1982): "Stein Rokkan: la teoria dello sviluppo politico europeo", en Stein Rokkan: Cittadini, elezioni, partiti, Il Mulino, Bologna.

Parsons, Talcott (1968): La estructura de la acción social, Guadarrama, Madrid.

Roberts, Kenneth y Eric Wibbels (1999): "Party Systems and Electoral Volatility in Latin America. A Test of Economic, Institutional and Structural Explanations", American Political Science Review, 93 (3), pp. 575-590.

Rokkan, Stein (1966): "Electoral Mobilization, Party Competition and National Integration", en Joseph LaPalombara y Myron Weiner (eds.): Political Parties and Political Development, Princeton University Press, Princeton, pp. 241-265.

(1967): "Cleavage Structures, Party Systems and Voter Alignments: An Introduction", en Seymour M. Lipset y Stein Rokkan (eds.): Party Systems and Voter Alignments, Free Press, New York.

(1975): "I voti contano le risorse decidono", Rivista Italiana di Scienza Politica, 5 (1), pp. 167-176.

(1980): "Territori, nazioni, partiti: verso un modello geopolitico dello sviluppo europeo", Rivista Italiana di Scienza Politica, 10 (3), pp. 437-470.

(1981): "Investigación trans-cultural, trans-societal y trans-nacional", en Raymond Boudon, Perre de Bie, Stein Rokkan y Eric Trist: Corrientes de investigación en las ciencias sociales. Los aspectos interdisciplinarios, Tecnos-Unesco, Madrid, pp. 175-238.

(2002): Stato, nazione e democracia in Europa (a cura di Peter Flora), II Mulino, Bologna.

Sartori, Giovanni (1984): “Dove va la scienza politica?", en Liugi Graziano (ed.): La scienza politica in Italia. Bilancio e prospettive, Franco Angeli, Milano, pp. 98-114. 
(1995): Ingegneria costituzionale comparata, II Mulino, Bologna.

(2004): “Hacia dónde va la ciencia política”, Política y Gobierno, 11 (2), pp. 349-354.

Scully, Timothy (1995): "Reconstituting Party Politics in Chile", en Scott Mainwaring y Timothy Scully (eds.): Building Democratic Institutions. Party Systems in Latin America, Stanford University Press, Stanford, pp. 100-137

Recibido: 22-11-2011

Aceptado: 22-12-2011 